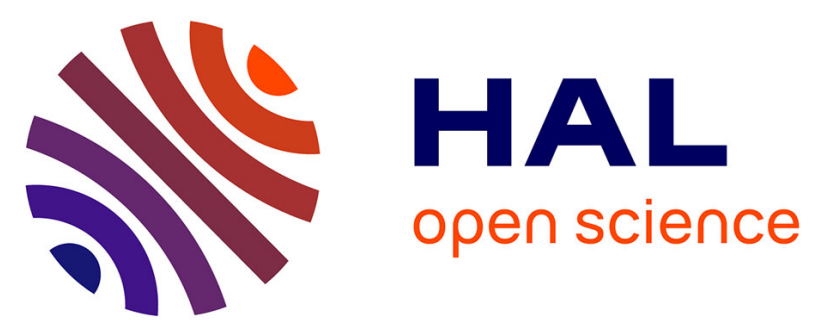

\title{
Thiol-Ene Linear Step-Growth Photopolymerization in Miniemulsion: Fast Rates, Redox-Responsive Particles, and Semicrystalline Films
}

\author{
Florent Jasinski, Agnès Rannée, Julie Schweitzer, Diane Fischer, Emeline \\ Lobry, Céline Croutxe-Barghorn, Marc Schmutz, Didier Le Nouen, Adrien \\ Criqui, Abraham Chemtob
}

\section{To cite this version:}

Florent Jasinski, Agnès Rannée, Julie Schweitzer, Diane Fischer, Emeline Lobry, et al.. Thiol-Ene Linear Step-Growth Photopolymerization in Miniemulsion: Fast Rates, Redox-Responsive Particles, and Semicrystalline Films. Macromolecules, 2016, 49 (4), pp.1143-1153. 10.1021/acs.macromol.5b02512 . hal-02442172

\section{HAL Id: hal-02442172 \\ https://hal.science/hal-02442172}

Submitted on 16 Jan 2020

HAL is a multi-disciplinary open access archive for the deposit and dissemination of scientific research documents, whether they are published or not. The documents may come from teaching and research institutions in France or abroad, or from public or private research centers.
L'archive ouverte pluridisciplinaire HAL, est destinée au dépôt et à la diffusion de documents scientifiques de niveau recherche, publiés ou non, émanant des établissements d'enseignement et de recherche français ou étrangers, des laboratoires publics ou privés. 


\title{
Thiol-Ene Linear Step-Growth Photopolymerization in Miniemulsion: Fast Rates, Redox-Responsive Particles, and Semicrystalline Films
}

\author{
Florent Jasinski, ${ }^{\dagger}$ Agnès Rannée, ${ }^{\dagger}$ Julie Schweitzer, $^{\dagger}$ Diane Fischer, $^{\dagger}$ Emeline Lobry,
} Céline Croutxé-Barghorn, ${ }^{\dagger}$ Marc Schmutz, ${ }^{\|}$Didier Le Nouen, ${ }^{\ddagger}$ Adrien Criqui, ${ }^{\perp}$ and Abraham Chemtob $*, \dagger, \S$

\author{
${ }^{\dagger}$ Laboratory of Photochemistry and Macromolecular Engineering and ${ }^{\ddagger}$ Laboratory of Organic and Bioorganic Chemistry, University \\ of Haute-Alsace, 3 bis rue Alfred Werner, 68093 Mulhouse, Cedex, France \\ ${ }^{\S}$ Institut de Science des Matériaux de Mulhouse, CNRS UMR 7361, 15 rue Jean Starcky, 68057 Mulhouse, France \\ "Institut Charles Sadron, CNRS, UPR 22, University of Strasbourg, 23 Rue du Loess, BP 84047, 67034 Strasbourg, Cedex 2, France \\ ${ }^{\perp}$ Mäder Research - MÄDER GROUP, 130 rue de la Mer Rouge, 68200 Mulhouse, France
}

Supporting Information

ABSTRACT: Radical step-growth photopolymerization of dithiol-diene monomer miniemulsion is shown to be a highly efficient, robust, and versatile route to generate film-forming linear poly(thioether) latexes. At extremely fast rates, the process results in high-molecular-weight polysulfide products, exhibiting both semicrystalline and oxidation-responsive properties. Four key issues are addressed as regards the practical implementation of this novel UV-driven waterborne technology: the preparation of a photolatent and colloidally stable thiol-ene monomer miniemulsion, the identification of key experimental parameters controlling reaction kinetics and polymer microstructure, the characterization of film semicrystallinity, and the application of poly(thioether ester) latexes as dual-stimuli-responsive nanocarriers sensitive to both oxidation and hydrolysis.

\section{INTRODUCTION}

Waterborne heterogeneous polymerization encompasses a number of processes; common to all of them is a polymer dispersion product used as coating vehicle or recovered as dry resin. ${ }^{1,2}$ When the usage of water is permitted, it is usually the preferred industrial method due to distinctive advantages. ${ }^{3}$ First, high molecular weight (MW) polymers can be produced in reasonable reaction times. Second, monomer can be added throughout the polymerization in semibatch operations to maintain copolymer composition. The other key features include a lower price production process over alternative methods (solution, bulk), easy-to-handle low viscous product, and an aqueous continuous phase improving the green credential of the process.

However, this eco-efficient technology has flourished almost exclusively on the ground of a single polymerization mechanism: radical chain-growth polymerization. In recent years, great efforts have been made to expand to more watersensitive polymerizations: ionic $^{4}$ and catalytic ${ }^{5}$ chain-growth polymerizations, even step-growth polymerizations. ${ }^{6}$ Despite these efforts, commercial processes based on nonradical alternatives are still scarce, and free radical polymerization has now been widely accepted as an inherent limitation of largescale waterborne heterogeneous polymerization. This strongly impacts the versatility in terms of copolymer composition and final properties for the material made from aqueous dispersions. To achieve new film properties, the main response has been an improved control of polymer architecture ${ }^{7,8}$ or hybrid colloids 9 prepared with preformed non-vinyl polymers. Additionally, the chemical industry addressed the lack of diversity with the addition of auxiliary monomers. ${ }^{10}$ Used in a small proportion $(<5 \%)$ and often based on functional acrylates, their role is to impart film with specific cross-linking, adhesion, or hydrophobic properties.

Following the seminal work of Marvel et al. in the 1940s, ${ }^{11}$ we have focused our attention on thiol-ene step-growth polymerization as a novel route to polymer dispersions. Of primary importance is the water tolerance of the active species exploited for a wide range of purposes, ${ }^{12}$ including the synthesis of hydrogels. ${ }^{13}$ Both propagation and transfer reactions governing polymer evolution rely indeed on thiyl and carbo radicals, respectively (see detailed mechanism in Scheme S1 of the Supporting Information). This is in sharp contrast with previous investigations on nonradical polymerization processes where the main challenge has been to overcome water sensitivity. In 2012, Shipp et al. have revived the subject's

Received: November 20, 2015

Revised: January 27, 2016

Published: February 2, 2016 
interest, ${ }^{14}$ and several groups have since experienced the unique advantages of thiol-ene polymerization in dispersed medium: fast rates in the matter of seconds, ${ }^{15}$ easy thiol or alkene particle functionalization, ${ }^{16,17}$ ambient temperature reaction, ${ }^{18}$ semicrystallinity of the resulting poly(thioether), ${ }^{15}$ etc. Suspension polymerization $^{17-19}$ and microfluidic techniques were implemented to synthesize microparticles, while miniemulsion polymerization ${ }^{15,16}$ resulted in nanosized particles. The success of this approach gave birth to variant click chemistry approaches based on thiol-acrylate Michael addition ${ }^{20,21}$ and thiol-yne $\mathrm{e}^{22}$ or thiol-isocyanate ${ }^{23}$ chemistry. Additionally, most of these studies employed a UV photochemical initiation providing spatiotemporal control and energy-saving process. Nevertheless, monomers with more than two functional groups per molecule were present, resulting with the formation of polymer network. The main caveat is that highly cross-linked polymer particles have far fewer uses than linear analogues because film forming ability or processability are generally more limited. Their niche applications cover chromatographic columns, ion exchangers, functional beads for medical diagnostics, support materials, calibration standards, and drug delivery carriers.

To fully tap the potential of thiol-ene emulsion photopolymerization, bifunctional monomers are needed as precursors of linear polymer particles having film-forming ability after water evaporation or flow properties after latex coagulation. Such polymers could be used as thermoplastic resins but also in all the conventional applications of emulsion polymer dispersions, including adhesives, paints, binders for nonwoven fabrics, additives for paper, textiles and construction materials, and impact modifiers for plastic. ${ }^{2}$ However, the successful synthesis of high-MW linear polymers using any step-growth polymerization reaction is more challenging than the corresponding small molecule or cross-linking reaction, since high MW values can be achieved only at very high conversions (>98-99\%). The need for very high conversions places several stringent requirements on any coupling reaction to be used for step-growth polymerization. This has been achieved by only handful of commercially important polymers (polyester, polycarbonate, or polyamide) under conditions not easily transposable in water because of high activation energy and often equilibrium condensation processes. In a recent letter, we have proved that these stringent conditions could be fulfilled during the photopolymerization of dithiol-diene monomer miniemulsion. ${ }^{15}$ In this new contribution, we present a detailed study of this system. Starting with two pairs of thiolene bifunctional monomers given in Scheme 1, we present extensive characterization, including real-time Fourier transform near-infrared (RT-FTNIR) spectroscopy, nuclear magnetic resonance (NMR), cryo-transmission electron microscopy (cryo-TEM), X-ray diffraction (XRD), polarized optical microscopy (POM), and differential scanning calorimetry (DSC), which provides insight into four key issues for the practical implementation of this novel UV emulsion technology: (i) the preparation of a monomer miniemulsion combining chemical and colloidal stability, (ii) the review of the main experimental parameters (irradiance, solid contents, etc.) controlling reaction kinetics and polymer microstructure, (iii) the characterization of polymer semicrystallinity, and (iv) the assessment of poly(thioether ester) particles as dual oxidation- and hydrolysis-responsive nanomaterials.
Scheme 1. Two Couples of Thiol-Ene Bifunctional Monomers (EDDT-DAP: 1; EDDT-DAA: 2) and the Corresponding Poly(thioether) Structure (P1 and P2) Formed by Step-Growth Linear Polymerization

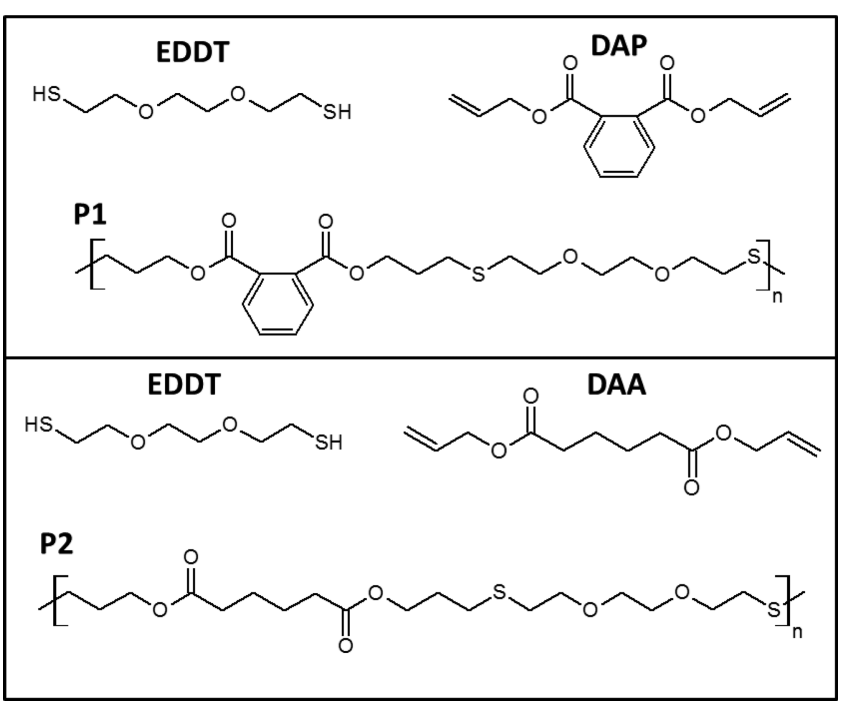

\section{EXPERIMENTAL SECTION}

Chemicals. 2,2-(Ethylenedioxy)diethanethiol (EDDT, TCI Chemicals, 95\%), diallyl phthalate (DAP, TCI Chemicals, 98\%), and diallyl adipate (DAA, TCI Chemicals, 98\%) were used as monomers. The two couples EDDT-DAP (1) and EDDT-DAA (2) gave birth to two poly(thioether ester) P1 and P2, as shown in Scheme 1. Distilled water was used for the preparation of the continuous phase of the miniemulsion. Hexadecane (HD, Aldrich, 98\%) and sodium dodecyl sulfate (SDS, Aldrich, 98\%) were respectively used as costabilizer and surfactant. Type I photoinitiators (PI), 2-hydroxy-4'-(2-hydroxyethoxy)-2-methylpropiophenone (I2959, BASF, 98\%) and 2,2dimethoxy-2-phenylacetophenone (I651, BASF, 99\%), ensured the generation of initiating radicals. 2,5-Di-tert-butylhydroquinone (DBHQ Aldrich, 99\%) was used as radical inhibitor. A 10 wt \% hydrogen peroxide solution (Aldrich) and a hydrochloric acid solution $(\mathrm{pH}=2)($ Fluka) were prepared for experiments on polysulfide latex degradation. In the latter, a commercial poly(acrylate- $b$-styrene) latex (UCAR poly(ester-b-acrylate) latex, Dow Chemicals) was used as a benchmark dispersion $\left(D_{\mathrm{p}} \approx 150 \mathrm{~nm}\right)$. Dimethyl sulfoxide (DMSO, Aldrich) was used as solvent for bulk polymerization and tetrahydrofuran (THF, Aldrich) as the solvent for size exclusion chromatography (SEC). All aforementioned chemicals were used without further purification.

Thiol-Ene Monomer Miniemulsion Preparation. Dithiol (EDDT) and diallyl (DAP or DAA) compounds were mixed together to obtain the monomer phase $\left(4 \mathrm{~g}, C_{\text {monomer }}=20 \mathrm{wt} \%\right)$. Mixtures were prepared so as to obtain a 1:1 stoichiometry in thiol and ene functions, taking into account the purity of the chemicals. $\mathrm{HD}$ was added to the monomer phase $\left(0.16 \mathrm{~g}, 4 \mathrm{wt} \% / C_{\text {monomer }}\right)$. In certain experiments, 6 drops $(0.3 \mathrm{~mL})$ of a DBHQ solution in acetone $(600$ ppm, $6 \times 10^{-4} \mathrm{~g} / \mathrm{L}$ ) were added to the mixture. The continuous phase consists of distilled water $(16 \mathrm{~g})$, SDS $\left(0.14 \mathrm{~g}, 3.5 \mathrm{wt} \% / C_{\text {monomer }}\right)$, and the water-soluble PI, I2959 $\left(0.08 \mathrm{~g}, 2 \mathrm{wt} \% / C_{\text {monomer }}\right)$. Both monomer and aqueous phases were stirred together for $10 \mathrm{~min}$ at $600 \mathrm{rpm}$. The miniemulsion was prepared subsequently by homogenizing the resultant coarse emulsion for 5 min using ultrasonication (Branson Sonifier $450 \mathrm{~W}$, amplitude $90 \%$ ) while maintaining stirring.

Thiol-Ene Miniemulsion Photopolymerization. The thiolene monomer miniemulsion was placed in a dismountable spectroscopic quartz cell of $1 \mathrm{~mm}$ optical path (volume $0.34 \mathrm{~mL}$, no stirring). Photopolymerization was triggered using the polychromatic $\mathrm{UV}$-vis light of a medium pressure $\mathrm{Hg}-\mathrm{Xe}$ arc lamp (Hamamatsu L8252, $200 \mathrm{~W}$ ). The quartz cell was irradiated vertically using a flexible 
light guide ensuring a homogeneous irradiation. A semielliptical mirror or reflector at $365 \mathrm{~nm}$ was used to enhance irradiance at this corresponding wavelength. Additionally, UV light below $310 \mathrm{~nm}$ was filtered using a long pass filter in order to avoid thiol self-initiation. Control experiments were undergone to check that there was no selfinitiated polymerization with the filtered irradiation. In the 310-600 $\mathrm{nm}$ wavelength emission range, an output irradiance of $590 \mathrm{~mW} \mathrm{~cm}{ }^{-2}$ was measured by radiometry (Ocean Optics HR4000 spectrometer). Note that this irradiation setup was also coupled with RT-FTNIR spectroscopy to assess the photopolymerization kinetics.

Poly(thioether ester) Latex Degradation. After polymerization, P1 and P2 latexes (20 wt \% of polysulfide) were diluted 20 times in a hydroperoxide aqueous solution (10 wt \%) or hydrochloric solution $(\mathrm{pH}=2)$ depending on the degradation route considered. A similar procedure was performed with polystyrene-based latex (UCAR) to provide benchmark experiments. Diluted latexes samples were continuously stirred then taken at different time, inserted in a $1 \mathrm{~cm}$ optical path quartz cuvette, and analyzed by UV-vis spectroscopy.

Methods. Monomer conversion was followed in situ by RT-FTNIR in rapid scan mode (temporal resolution: $0.5 \mathrm{~s}$; spectral resolution: 4 $\mathrm{cm}^{2}$ ). The spectroscopic cell containing the miniemulsion was irradiated simultaneously by a NIR probe beam and a UV exciting beam (see Scheme S2 in the Supporting Information). The NIR region $\left(970-1940 \mathrm{~nm}, 9000-4000 \mathrm{~cm}^{-1}\right.$ ) is well suited to aqueous miniemulsions because high water concentrations can be accommodated without detector saturation. Ene conversion relied on an specific absorption band at $4484 \mathrm{~cm}^{-1}$, which is assumed to be a combination of two $\mathrm{C}-\mathrm{H}$ stretching bands. ${ }^{24}$ By contrast, the measurement of thiol conversion was not found to be possible because of the absence of well-defined vibrational modes in the NIR region. Polymerization kinetics were assessed in situ by integrating the attenuance of the ene band and monitoring its decrease during irradiation. The limited signal-to-noise ratio, especially at high conversion, provided motivation to fit the conversion-time plots using a sigmoidal function described in ref 25. A typical experimental conversion-time plot and its fitted homologue are shown in Figure S1 of the Supporting Information.

Thiol-ene miniemulsion stability was assessed using multiple-light scattering (Turbiscan LAB, Formulaction). In a typical measurement, $20 \mathrm{~mL}$ of freshly prepared miniemulsion was placed in a vial and placed in the instrument. The temporal evolution of the backscattered light intensity (reflectance) normalized with respect to a nonabsorbing standard reflector was assessed during $3.5 \mathrm{~h}$ at $25^{\circ} \mathrm{C}$. The evolution of the backscattered light (at $45^{\circ}$ from the incident beam) was determined by scanning the entire volume of the miniemulsion from the bottom to the cap of the cell. ${ }^{26}$ Measurements were taken at the middle of the vial $(\approx 20 \mathrm{~mm})$. Droplet and particles diameters, respectively labeled as $D_{\mathrm{d}}$ and $D_{\mathrm{p}}$, were determined through dynamic light scattering (DLS) using a Zetasizer Nano ZS (Malvern Instrument). Thiol-ene miniemulsion and polymerized latex were diluted 125 times in filtered and distilled water before analysis.

$\mathrm{UV}$-vis attenuance spectra of thiol-ene miniemulsions, solutions in DMSO, and diluted latexes used in degradation experiments were all recorded with a double-beam SPECORD 210 BU UV-vis spectrometer (Analytic Jena AG).

Molecular weights were determined by SEC. Prior to analysis, 1-2 drops of the polymer latex was directly dissolved in $1 \mathrm{~mL}$ of THF to avoid the onset of insoluble crystalline parts. The analysis was performed on a Shimadzu LC-20AD liquid chromatograph equipped with two Varian PL gel $5 \mu \mathrm{m}$ MIXED-C columns (column, injection, and refractometer temperature: $30^{\circ} \mathrm{C}$; injection volume: $100 \mu \mathrm{L}$ ) and a refractive index detector (Shimadzu RID-10A). THF was used as the eluent at a flow rate of $1.0 \mathrm{~mL} / \mathrm{min}$. The $\bar{M}_{\mathrm{n}}$ and $Ð=\overline{M_{\mathrm{w}}} / \overline{M_{\mathrm{n}}}$ values were determined relative to linear polystyrene calibration standards.

The DSC experiments (DSC Q200, TA Instruments) were performed under a nitrogen atmosphere $(50 \mathrm{~mL} / \mathrm{min})$ using either dry latex or as-synthesized liquid latexes. In both cases, the sample (8 $\mathrm{mg}$ ) was placed within an aluminum hermetic pan, which was heated/ cooled at $10{ }^{\circ} \mathrm{C} / \mathrm{min}$. Thermogravimetric analysis (TGA) (TGA Q500, TA Instruments) was carried out under a nitrogen atmosphere
$(20 \mathrm{~mL} / \mathrm{min}) .9 \mathrm{mg}$ of the dry polysulfide film was placed in an open aluminum pan and heated from ambient conditions to $1000{ }^{\circ} \mathrm{C}$ at 10 ${ }^{\circ} \mathrm{C} / \mathrm{min}$.

In POM analysis, the polysulfide latexes were coated using a $1 \mu \mathrm{m}$ calibration bar at ambient temperature on glass plates and left drying at ambient temperature for $24 \mathrm{~h}$. Resultant polysulfide films were then analyzed by POM with an Olympus Statif BX51 microscope. Glass plates were placed in a heating cell (Linkam LTS350) coupled with the microscope, and the cell temperature was controlled (Linkam TP94). Polysulfide films were heated at $10{ }^{\circ} \mathrm{C} / \mathrm{min}$ from 15 to $130{ }^{\circ} \mathrm{C}$. Images were taken using the acquisition software $\mathrm{Cell}^{\wedge} \mathrm{A}$.

XRD patterns were recorded on a X'Pert Pro diffractometer (PANalytical) equipped with a copper tube $\left(\mathrm{K} \alpha_{1-2}=0.15418 \mathrm{~nm}, 45\right.$ $\mathrm{kV}$, and $40 \mathrm{~mA}$ ) and a linear detector X'Celerator (active length = $2.122^{\circ} 2 \theta$ ). Dried polysulfide latex samples were coated on zero background plates (silicon) and then fixed in a specific sample holder with modeling clay. Diffractograms were recorded at high angles at ambient temperature for angle ranging from $3^{\circ}$ to $50^{\circ} 2 \theta$ with $0.017^{\circ}$ $2 \theta$ path and time per path of $220 \mathrm{~s}$ (wide-angle XRD). Total analysis time was $1.5 \mathrm{~h}$. In order to visualize reflexions lower than $3^{\circ} 2 \theta$, smallangle recording were realized from $0.5^{\circ}$ to $10^{\circ} 2 \theta$ (path and time per path identical to high angles). On the X-ray beam path was mounted as primary optics: Soller slits of $0.04 \mathrm{rad}$, a divergent slit of $1 / 16(1 / 32$ for small angles), a mask of $10 \mathrm{~mm}$, and an antiscattering slit of $1 / 8$ ( $1 / 16$ for small-angle). As secondary optics: a receptor slit of $5 \mathrm{~mm}$, Soller slits of $0.04 \mathrm{rad}$, and a nickel filter. All samples were put under rotation (1 rps) during spectrum acquisition.

For NMR analysis, the as-synthesized polysulfide latexes $(0.05 \mathrm{~mL})$ were directly added to an NMR tube without deuterated solvent for NMR analysis to hinder crystallization. ${ }^{1} \mathrm{H}(400 \mathrm{MHz})$ was obtained on a Bruker Advance 400 at $295 \mathrm{~K}$ using tetramethylsilane (TMS) as internal standard.

For cryo-TEM analysis, a 400 carbon lacey film (Ted Pella) was rendered hydrophilic with a glow discharge treatment (Elmo Cordouan), a $5 \mu \mathrm{L}$ drop was deposited onto the grid, and the film was blotted and plunged-freezed with a homemade freezing machine. The humidity and $T$ are controlled at $>80 \%$ and $23{ }^{\circ} \mathrm{C}$, respectively. Subsequently, the grid was then transferred onto a Gatan 626 cryoholder and observed under low dose conditions in a Tecnai G2 under $200 \mathrm{kV}$. Images were recorded with an Eagle $2 \mathrm{k} 2 \mathrm{k}$ ssCCD camera (FEI).

\section{RESULTS AND DISCUSSION}

The starting monomer miniemulsion (20 wt \% monomer content) is based on a stoichiometric amount of bifunctional A-A (thiol) and B-B (ene) monomers. 2,2-(Ethylenedioxy)diethanethiol (EDDT) was chosen as dithiol while diallyl adipate (DAA) or phthalate (DAP) forms the two possible dialkene comonomers (chemical structures shown in Scheme 1). The analysis, in parallel, of these two miniemulsions (M1: EDDT-DAP; M2: EDDT-DAA) enables a critical approach. The choice of allyl ether functions is dictated by their inability to homopolymerize because a stable allylic radical is formed. This suppresses the risk of stoichiometric imbalance of reactants that may drastically lower the polymer MW. In addition to monomers, HD and SDS serve as stabilizers against Ostwald ripening and coalescence, respectively, as conventionally reported for a miniemulsion formulation. ${ }^{27} \mathrm{~A}$ water-soluble $\alpha$-hydroxy ketone type I PI (I2959) is also introduced in the aqueous phase.

Thiol-Ene Monomer Miniemulsion: Chemical and Colloidal Stability. Prior to photopolymerization, there are two important aspects with thiol-ene monomer miniemulsion with regard to chemical and colloidal stability.

Chemical Stability. Premature reaction, i.e., before UV exposure, is generally managed in free radical photopolymerization of acrylate or styrene monomers by avoiding exposure to 
light or heat. By contrast, this is a significant issue in thiol-ene chemistry because of the relatively high rates of polymerization. Obviously, the main reason for thiol-ene reaction efficiency also accounts for the adventitious initiation, mostly induced by radical traces. ${ }^{28,29}$ As shown in Table 1, both organic mixtures

Table 1. Data on Chemical and Colloidal Stability of ThiolEne Pairs 1: EDDT-DAP and 2: EDDT-DAA in Bulk and Miniemulsion Form

\begin{tabular}{|c|c|c|c|c|}
\hline $\begin{array}{l}\text { thiol-ene } \\
\text { pair }\end{array}$ & form & $\begin{array}{c}\text { ene conv } \\
(\text { after } 1 \mathrm{~h})^{a}(\%)\end{array}$ & $\begin{array}{c}D_{\mathrm{d}} \\
(\mathrm{nm})\end{array}$ & $\begin{array}{c}D_{\mathrm{d}}(\operatorname{after} 1 \mathrm{~h})^{a} \\
(\mathrm{~nm})\end{array}$ \\
\hline \multirow{4}{*}{$\begin{array}{l}\text { EDDT- } \\
\text { DAP }\end{array}$} & bulk 1 & 24 & & \\
\hline & $\mathrm{M} 1^{b}$ & 56 & 190 & 205 \\
\hline & $\begin{array}{l}\text { bulk } 1+40 \mathrm{ppm} \\
\text { DBHQ }\end{array}$ & 5 & & \\
\hline & $\begin{array}{l}\mathrm{M}^{b}+40 \mathrm{ppm} \\
\mathrm{DBHQ}\end{array}$ & 15 & 155 & 160 \\
\hline \multirow{4}{*}{$\begin{array}{l}\text { EDDT- } \\
\text { DAA }\end{array}$} & bulk 2 & 45 & & \\
\hline & $\mathrm{M} 2^{b}$ & 73 & 190 & 170 \\
\hline & $\begin{array}{l}\text { bulk } 2+40 \text { ppm } \\
\text { DBHQ }\end{array}$ & 47 & & \\
\hline & $\begin{array}{l}\mathrm{M} 2^{b}+40 \mathrm{ppm} \\
\mathrm{DBHQ}\end{array}$ & 77 & 170 & 170 \\
\hline
\end{tabular}

${ }^{a}$ Data determined $1 \mathrm{~h}$ after the emulsification. Conversion values were given by FTIR and droplet size by DLS. ${ }^{b}$ The aqueous phase of the miniemulsion contains the PI.

EDDT-DAP (1) and EDDT-DAA (2) prepared without PI significantly suffer from premature polymerization, with respectively $24 \%$ and $45 \%$ ene conversion (FTIR data) after $1 \mathrm{~h}$ storage at ambient temperature without exposure to light. Both dienes have similar functional groups (electron-rich allyl propionate) and only differ from the bridging group: phenyl (DAP) or butylene (DAA). Lower or more difficult solubility of the higher-molecular-weight reactants produced in the DAPEDDT system may be responsible for the observed, apparent lower reactivity. The formation of miniemulsion from these two organic monomer phases further increases the consumption ( $56 \%$ in $\mathrm{M1}$ and $73 \%$ in M2 after $1 \mathrm{~h}$ ). The PI present in the aqueous phase of the miniemulsion is not responsible for this drift, as checked by control experiments performed without this component. More probably, a supplement of initiating radicals may be produced by ultrasonic cavitation through decomposition of water, monomer, surfactant, or impurities as reported in the literature. ${ }^{30}$ While this limited shelf life undermines temporal control of the reaction, the long-term photolatency in our miniemulsion thiol-ene photopolymerization is less crucial than in a conventional UV-curable formulation. The main reason is that step-growth polymerization of bifunctional monomers is manifested by a slow increase of molecular weight evolution with impossibility of gelation. $^{16}$

Despite these considerations, the improvement of chemical stability remains important to avoid run-to-run irreproducibility. In fact, a gradual increase in MW of the monomer phase to be emulsified, although proceeding slowly, changes composition and viscosity. The consequences are large discrepancies of several tens of nanometers in average droplet size when changing the time between organic phase preparation and emulsification (data not given) and notably a tendency to obtain larger droplet diameters and broader size distributions when this time is lengthened. These latter results were assigned to a poorer efficiency of droplet breakup when the organic monomer phase becomes more viscous. ${ }^{31}$ Based on the recent findings of Liska et al., ${ }^{28}$ a possible solution to improve chemical stability, and indirectly repeatability and reproducibility, is the addition of a conventional phenolic radical stabilizer (DBHQ).

Table 1 shows that DBHQ (ca. $40 \mathrm{ppm}$ ) behaves as an efficient stabilizer for the less reactive EDDT-DAP system, either in bulk or in miniemulsion form, with ene conversions limited to $5 \%$ and $15 \%$ after $1 \mathrm{~h}$, respectively. In addition, the resulting miniemulsion $\mathbf{M 1}$ containing the radical inhibitor exhibited a smaller average droplet diameter (155 nm) compared to the analogue without stabilizer $(190 \mathrm{~nm})$, and an acceptable level of repeatability was found (standard deviation of $7 \mathrm{~nm}$ calculated from five replicates; see the collection of data in Table S1 of the Supporting Information). By contrast, the addition of DBHQ to the more reactive EDDT-DAA couple showed no improvement of shelf life stability for the bulk and the miniemulsion because of the difficulty to manage its higher reactivity. Accordingly, the preparation of the miniemulsion $\mathbf{M} 2$, repeated five times, led to $D_{\mathrm{d}}$ values ranging from 150 to $200 \mathrm{~nm}$ (standard deviation $=16$ $\mathrm{nm})$. Although this poor repeatability does not prevent the photopolymerization of M2, caution must be taken in the interpretation of the results.

Colloidal Stability. Figure 1 is a plot of the average droplet diameter $D_{\mathrm{d}}$ (y right ordinate) and reflectance $R$ ( $y$ left

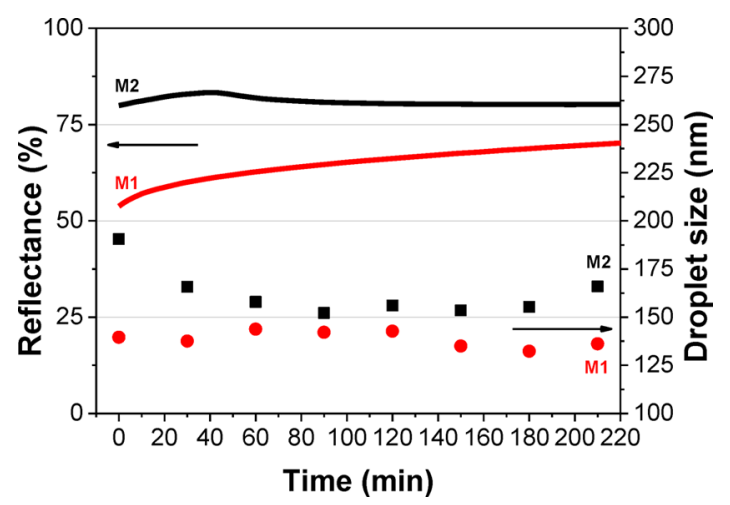

Figure 1. Reflectance values determined at the middle of the vial (left $y$ axis, line) and droplet average diameter values (right $y$ axis, dot) as a function of storage time for the two thiol-ene miniemulsions: M1 (red) and M2 (black). $C_{\text {monomer }}=20 \mathrm{wt} \%$; both miniemulsions contain DBHQ inhibitor.

coordinate) as a function of storage time $(4 \mathrm{~h})$ for the two miniemulsions M1 and M2 containing DBHQ. The temporal variation of these two values, obtained independently by DLS $\left(D_{\mathrm{d}}\right)$ and backscattering measurements $(R)$, can be linked to the colloidal stability. In both instances, the evolution of the miniemulsion's average droplet size given by DLS measurement is not very significant within $4 \mathrm{~h}$, but larger variations are found with the chemically instable sample (M2) compared to the photolatent one (M1) within $1 \mathrm{~h}$ after emulsification. Because dilution is not necessary, the reflectance data seem more accurate to detect droplet size change and/or local concentration variation because of sample colloidal destabilization. Once again, both backscattering profiles are in line with an acceptable stability of the two samples. However, we note that the reflectance profile of $\mathbf{M} 2$ remains almost unchanged within $4 \mathrm{~h}$, indicating a superior colloidal stability compared to M1. As 
previously mentioned, premature polymerization of M2 causes a significant consumption of monomer and consequently a depletion of the primary vector for Ostwald ripening. ${ }^{32}$ Because it combines a reasonable chemical and colloidal stability, M1 has been selected in the following part, where the influence of various experimental parameters was examined. Note that all miniemulsions were photopolymerized within $5 \mathrm{~min}$ after preparation in the rest of the study.

Influence of Different Parameters on Miniemulsion Photopolymerization. Comparison between Bulk, Solution, and Miniemulsion Conditions. Miniemulsion features a droplet size $(50-500 \mathrm{~nm})$ substantially smaller than a conventional macroemulsion $(0.1-20 \mu \mathrm{m})$. While the resultant decrease in scattering is desirable to mitigate nonuniform irradiation within the sample, the average droplet size reached by $\mathrm{M1}\left(D_{\mathrm{d}}=155 \mathrm{~nm}\right)$ for example makes monomer miniemulsion nonetheless opaque to the naked eye. To investigate more quantitatively the extent of scattering and its effect on light depth, Figure $2 \mathrm{~A}$ shows the attenuance spectrum
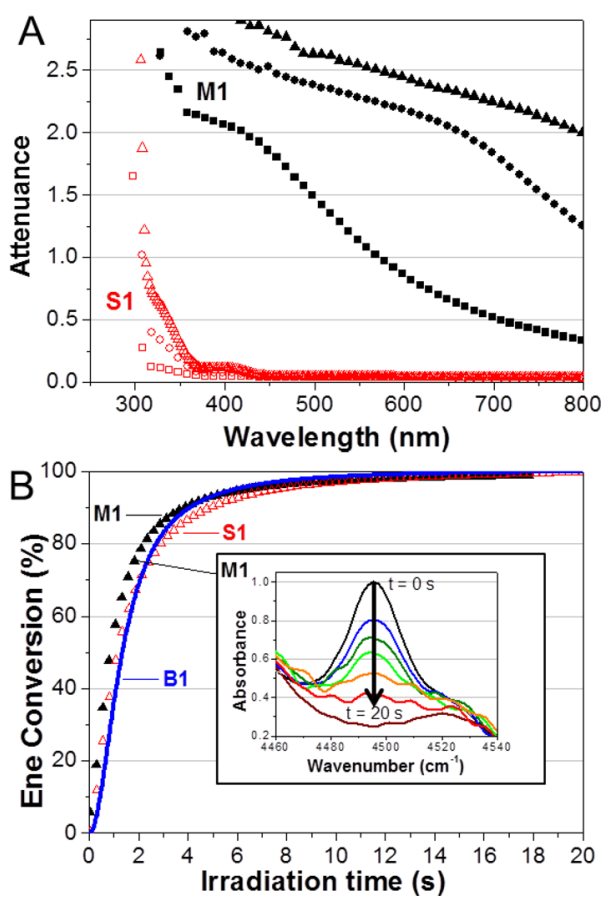

Figure 2. (A) Attenuance spectra of miniemulsion M1 (full symbols) and solution homologue $\mathbf{S} 1$ in DMSO (empty symbols) with $C_{\text {monomer }}$ $=20 \mathrm{wt} \%$ at different optical paths: $1 \mathrm{~mm}$ (triangle), $0.5 \mathrm{~mm}$ (circle), and $0.1 \mathrm{~mm}$ (square). (B) Conversion-times curves profiles for M1 (full symbols), S1 (open symbols), and bulk system B1 (solid line). All photopolymerizations were performed in a $1 \mathrm{~mm}$ thick spectroscopic cell under UV light provided by a filtered mercury-xenon arc lamp $(\lambda$ $>310 \mathrm{~nm}, I=590 \mathrm{~mW} \mathrm{~cm}^{-2}$ ). The inset shows a series of NIR spectra of M1 during photopolymerization.

of $\mathrm{M1}$ at three different optical paths $(0.1,0.5$, and $1 \mathrm{~mm})$ as well as a comparison with a solution analogue $\mathbf{S 1}$ in which water was replaced by DMSO. In the visible range, M1 shows high attenuance values assigned only to scattering, whereas S1 is transparent. In the UV region, there is a superimposition of scattering and absorption (due to monomer and PI), leading to much higher attenuance values in M1 with respect to S1. Attenuance is even too high to be detected for the thickest samples $(\geq 0.5 \mathrm{~mm})$. At $350 \mathrm{~nm}$ corresponding to the threshold value below which the acetophenone-derivative PI absorbs, less than $1 \%$ of the incident photons are transmitted beyond 0.1 $\mathrm{mm}$ of the optical path (versus $80 \%$ in solution). As a result, at the beginning of the irradiation, only a minority of the actinically relevant UV photons are transmitted beyond a few tens of micrometers of the optical path. To improve significantly light penetration (without changing PI concentration), sub-100 nm monomer droplets exhibiting a narrow enough size distribution would be necessary. However, the control of these two parameters is very challenging during emulsification.

Using a $1 \mathrm{~mm}$ thick spectroscopic cell as photoreactor, M1 and S1 were photopolymerized at room temperature, without stirring, and under continuous UV irradiation of a conventional medium-pressure $\mathrm{Hg}$ arc lamp for only $20 \mathrm{~s}$. Figure 2B shows the reaction kinetics monitored in situ by RT-FTNIR spectroscopy through the decay of the ene absorption band at $4484 \mathrm{~cm}^{-1}$ over time (see the inset). Remarkably, there are no noticeable differences of polymerization rates between these two systems. Additionally, a control experiment in bulk (B1) did not alter the kinetic profiles, confirming the minor role played by the organic solvent. Therefore, the miniemulsion photopolymerization may be not diffusion limited, suggesting that the rates of diffusion of monomer droplets to the irradiated areas are faster than the rate of reaction of the two functional groups. This indicates that an efficient mass transfer may overcome the limited depth of light penetration. Nevertheless, the equivalence between M1, S1, and B1 was obtained in specific conditions that thicker optical path reactors, larger droplets, or higher concentration could jeopardize. Another key feature is the very high conversion rates: a full conversion was accomplished in less than $15 \mathrm{~s}$. As a result, thiol-ene chemistry holds a high potential for fast polymerization under mild conditions, which is a notable exception in linear step-growth polymerization. Of paramount importance is that high kinetic coefficients in the range of $10^{5}-10^{6} \mathrm{~L} \mathrm{~mol}^{-1} \mathrm{~s}^{-1}$ are found for a broad classes of terminal thiol and ene monomers regardless of their other structural features. ${ }^{33}$ This is not true for chain radical polymerization where very high values of propagation rate coefficient $\left(k_{\mathrm{p}}\right)$ are found only with some specific monomers such as acrylates (e.g., butyl acrylate $k_{\mathrm{p}}=13000$ $\mathrm{L} /(\mathrm{mol} \mathrm{s})$ at $\left.50{ }^{\circ} \mathrm{C}\right)$ versus much lower values for methacrylates (methyl methacrylate: $648 \mathrm{~L} /(\mathrm{mol} \mathrm{s})$ at $50{ }^{\circ} \mathrm{C}$ ) or styrene $\left(160 \mathrm{~L} /(\mathrm{mol} \mathrm{s})\right.$ at $\left.40{ }^{\circ} \mathrm{C}\right) .{ }^{34}$

Table 2 summarizes the results of the three polymerizations M1, S1, and B1 as regards with conversion, molecular weight $\left(\overline{M_{\mathrm{n}}}, \overline{M_{\mathrm{w}}}\right.$, and $\left.\boxplus\right)$, and colloidal properties when it is relevant. ${ }^{1} \mathrm{H}$ NMR spectroscopy (see spectrum in Figure S2) of the obtained polymers unambiguously confirmed the formation of the desired poly(thioether) and the very high ene conversion in agreement with the FTIR data. In addition, SEC data show polydispersity index between 2 and 3 as well as $\overline{M_{n}}$ values higher than $10 \mathrm{kDa}$ regardless of the method (see SEC traces in Figure S3). This result shows that thiol-ene chemistry using $\mathrm{AA}$ and $\mathrm{BB}$ monomers is well-suited for step-growth polymerization, even without monomer purification. Significantly higher MW values were realized in $\mathbf{M 1}\left(\bar{M}_{\mathrm{n}}=20.3 \mathrm{kDa}\right)$ in comparison with $\mathbf{S 1}(11.0 \mathrm{kDa})$ and $\mathbf{B 1}(11.6 \mathrm{kDa})$. It is suggested that a radical compartmentalization (or segregation) effect may take place, similarly as chain polymerization. A propagating radical in a polymer particle isolates it from other propagating radicals and allows growth to higher MW than might be achieved in solution or bulk polymerization (provided 
Table 2. Effect of Polymerization Method (Miniemulsion, Solution, and Bulk) on Kinetic, Colloidal, and Polymer Properties for the EDDT-DAP System

\begin{tabular}{|c|c|c|c|c|c|c|c|}
\hline entry & ene conv ${ }^{a}(\%)$ & $D_{d}^{b}(\mathrm{~nm})$ & $D_{p}^{b}(\mathrm{~nm})$ & $N_{p} / N_{d}^{c}$ & $\bar{M}_{\mathrm{n}}^{d}(\mathrm{kDa})$ & ${\overline{M_{\mathrm{w}}}}^{d}(\mathrm{kDa})$ & $\boxplus^{e}$ \\
\hline B1 (bulk) & $>99$ & & & & 11.6 & 36.0 & 3.1 \\
\hline S1 (solution) & $>99$ & & & & 11.0 & 23.6 & 2.1 \\
\hline M1 (miniemulsion) & $>99$ & 160 & 153 & 1.07 & 20.3 & 54.3 & 2.7 \\
\hline
\end{tabular}

${ }^{a}$ Conversion of alkene function determined by FTIR data. ${ }^{b}$ Droplet $\left(D_{\mathrm{d}}\right)$ and particle $\left(D_{\mathrm{p}}\right) z$-average diameters as determined by DLS. ${ }^{c}$ Calculated by the equation $N_{\mathrm{p}} / N_{\mathrm{d}}=\left(\rho_{\text {monomers }} \times D_{\mathrm{d}}{ }^{3}\right)\left(\rho_{\text {polymer }} \times D_{\mathrm{p}}{ }^{3}\right) \rho_{\text {monomers }}$ is the density of EDDT-DAP (1.06). $\rho_{\text {polymer }}$ is the resulting poly(thioetherester) density (1.13) and was measured by pycnometry. ${ }^{d}$ Number-average $\left(\bar{M}_{\mathrm{n}}\right)$ and weight-average $\left(\bar{M}_{\mathrm{w}}\right)$ molar mass as determined by size exclusion chromatography. ${ }^{e}$ The breadth of molecular weight distribution also referred to as polydispersity index $Đ=\overline{M_{\mathrm{w}}} / \overline{M_{\mathrm{n}}}$.

Table 3. Effect of the Polymerization System, Irradiance $(250-600 \mathrm{~nm})$, Type of PI, and Monomer Content on Colloidal ( $D_{\mathrm{d}}$, $D_{\mathrm{p}}$, and $\left.N_{\mathrm{p}} / N_{\mathrm{d}}\right)$ and Kinetics

\begin{tabular}{|c|c|c|c|c|c|c|c|c|}
\hline entry & monomer content (wt \%) & irradiance $\left(\mathrm{mW} / \mathrm{cm}^{2}\right)$ & $\mathrm{PI}^{a}$ & ene conv $(\%, t=20 \mathrm{~s})$ & $R_{\mathrm{p}, \max }^{b}\left(\mathrm{~s}^{-1}\right)$ & $D_{\mathrm{d}}(\mathrm{nm})$ & $D_{\mathrm{p}}(\mathrm{nm})$ & $N_{\mathrm{p}} / N_{\mathrm{d}}$ \\
\hline A & 20 & 590 & water-soluble PI & $>99$ & 64 & 160 & 153 & 1.07 \\
\hline $\mathrm{B}$ & 20 & 590 & oil-soluble PI & $>99$ & 99 & 155 & 148 & 1.18 \\
\hline $\mathrm{C}$ & 20 & 295 & water-soluble PI & $>99$ & 44 & 145 & 137 & 1.11 \\
\hline $\mathrm{D}$ & 20 & 235 & water-soluble PI & 95 & 37 & 145 & 137 & 1.11 \\
\hline $\mathrm{E}$ & 20 & 145 & water-soluble PI & 92 & 26 & 145 & 138 & 1.08 \\
\hline $\mathrm{F}$ & 20 & 60 & water-soluble PI & 75 & 8 & 145 & 138 & 1.08 \\
\hline G & 25 & 590 & water-soluble PI & $>99$ & 39 & 147 & 141 & 1.06 \\
\hline $\mathrm{H}$ & 30 & 590 & water-soluble PI & 95 & 47 & 173 & 154 & 1.32 \\
\hline I & 35 & 590 & water-soluble PI & $>99$ & 162 & 161 & 154 & 1.07 \\
\hline $\mathrm{J}$ & 50 & 590 & water-soluble PI & $>99$ & 51 & 152 & 149 & 0.99 \\
\hline
\end{tabular}

${ }^{a}$ The water-soluble PI is I2959, and the oil-soluble one is I651. ${ }^{b} R_{\mathrm{p}, \max }$ were obtained by differentiation of the fitted conversion plot for each run.

that the rate of entry of another radical from the aqueous phase is sufficiently slow). ${ }^{35-37}$ However, achieving high $\mathrm{MW}$ in a step reaction with $\mathrm{AA}$ and $\mathrm{BB}$ monomers may seem more complex in dispersed medium because of the strong difference in water solubility between EDDT $(15 \mathrm{~g} / \mathrm{L})$ and DAP $(0.15 \mathrm{~g} /$ $\mathrm{L})$. Therefore, each individual droplet is likely to deviate compositionally from the exact stoichiometric balance. The fact that high MW polymers are created in the miniemulsion polymerization provides indirect evidence that the thiol reactant can diffuse from the aqueous phase to the particle and undergoes polymerization. It also reflects that oxidation of thiols to disulfides (also resulting in stoichiometric imbalance) plays a minor role. The resultant high monomer conversion drives high MW but also ensures a minimal amount of residual monomers, which is another positive effect of a step-growth polymerization. By contrast, in a chain mechanism, the unconverted reactive functionality necessarily derives from monomer molecules; therefore, a certain amount of monomer remains in the final material (several thousand parts per million typically in a conventional emulsion polymerization), raising toxicity concern, and requiring postpolymerization operations for their removal. ${ }^{3}$ In our step-growth process, the residual thiol or allyl groups are retained as end groups of nonvolatile polymer or oligomer chains, thereby reducing toxicity.

As far as colloidal properties are concerned, droplet $\left(D_{\mathrm{d}}=\right.$ $160 \mathrm{~nm})$ and particle size $\left(D_{\mathrm{p}}=155 \mathrm{~nm}\right)$ are very similar given the experimental error of DLS. From these data, a ratio of particle to droplet number was estimated to 1.07 , fully in line with an effective droplet nucleation and also indicative of minor destabilization. As emphasized earlier, step-growth polymerizations are characterized by the disappearance of monomer early in the reaction and far before the production of high MW polymer. As small monomer molecules are the main drivers of Ostwald ripening, diffusional degradation is rapidly suppressed in this mechanism because low-MW species have weaker mass transfer ability through the aqueous phase. The exact opposite is the case for chain-growth polymerizations, where monomer species are still present even at high conversions. Therefore, Ostwald ripening is suppressed only when a sufficient concentration of polymer is formed $(>30-40 \%) .^{38}$

Effect of Various Experimental Parameters. Table 3 shows the effect of PI solubility, irradiance, and solids content on ene conversion and reaction rates as well as colloidal properties $\left(D_{\mathrm{d}}\right.$ $D_{\mathrm{p}}, N_{\mathrm{p}} / N_{\mathrm{d}}$ ). Additionally, all the kinetic curves are provided in Supporting Information (Figure S4). A unique advantage of miniemulsion over other heterogeneous methods is the ability to use PI of different solubility in water. We replaced hydroxyacetophenone (run A), fully soluble in the aqueous phase by dialkoxyacetophenone (2,2-dimethoxy-2-phenylacetophenone, run B), a widely used type I ( $\alpha$-cleavable) PI exhibiting an enhanced water-insolubility and dissolved in the monomer phase. ${ }^{39}$ The difference between these two initiators involve not only solubility but also photochemical properties (quantum yield, triplet state lifetime, initiating radicals, absorption spectrum), making direct comparison of photopolymerization results difficult. However, it is surprising to note that the change of PI was not accompanied by any significant modification of polymerization rates and particle size, confirming the robustness of the present process. In addition, Table 3 emphasizes the effect of irradiance $\left(60-590 \mathrm{~mW} / \mathrm{cm}^{2}\right)$ on thiol-ene miniemulsion kinetics (runs $\mathrm{C}-\mathrm{F}$ ). There is a net accelerating effect related to the increase in irradiance until a threshold value of $150 \mathrm{~mW} / \mathrm{cm}^{2}$. The amount of absorbed photons determines the number of initiating radicals generated through PI cleavage. Upon decreasing irradiance, a lower number of initiating radicals is created; hydrogen abstraction on thiol functions decreases with fewer thiyl radicals generated. ${ }^{40}$ Therefore, the addition rate on double bonds is diminished. As expected, the irradiance variation has a minimal effect on the nucleation mechanism because of limited destabilization 
process, and similar $D_{\mathrm{p}}$ and $N_{\mathrm{p}} / N_{\mathrm{d}}$ values were obtained. In a last series of experiments, the organic phase content was progressively increased from $20 \%$ to $50 \%$. Runs G-J (Table 3) show the feasibility of conducting polymerization with organic phase contents up to $50 \%$, which is a remarkable feature. High solid content latexes are highly desired industrially. The principal advantages are an increased space-time yield of the reactor, more efficient product transport, and faster drying times during film application. ${ }^{41}$ In this series, the $N_{\mathrm{p}} / N_{\mathrm{d}}$ ratio remains close to unity, regardless the organic phase content. Additionally, there are no drastic changes on photopolymerization kinetics upon increasing the monomer concentration. Although miniemulsions of somehow similar average droplet sizes are generated, they differ from optical properties. A higher droplet concentration enhances scattering without undermining the polymerization rates. Again, this result suggests a nondiffusion-limited photopolymerization mechanism in agreement with the previous experiments. However, these observations remain qualitative, and the main challenge is the development of mechanistic models describing the interplay among UV radiation transfer in a scattering medium, photoreactor hydraulics, and intrinsic reaction kinetics. In this respect, an analogy can be drawn with $\mathrm{TiO}_{2}$ heterogeneous photocatalytic systems into which significant modeling efforts have been deployed recently for optimization of UV disinfection and oxidation photoreactors. ${ }^{42}$

Semicrystalline Poly(thioether) Film. The latexes derived from the polymerized miniemulsions $\mathbf{M} 1$ and $\mathbf{M} 2$ were good film forming at room temperature. One of the outstanding characteristics of the resultant poly(thioether) films $\mathbf{P 1}$ and $\mathbf{P 2}$ is the resistance to a wide range of solvents and chemicals at ambient temperature. The insolubility gives a first indication of their high crystallinity and melting point. The semicrystallinity of linear poly(thioether) is well documented in the literature, in particular as regards with poly(ethylene sulfide) and poly(propylene sulfide). ${ }^{43}$ By contrast, the latex particles can be dissolved in a water-miscible solvent such as THF (making SEC analysis possible). This result suggests indirectly that the polymer particles do not contain a high fraction of crystalline domains as they are synthesized. This phenomenon was also observed with poly(vinylidene chloride) copolymers produced by radical emulsion polymerization, in which a crystallization takes place during film formation. ${ }^{44}$ Another indirect proof of limited semicrystallinity in the latex form was given by cryo-TEM images (Figure 3) showing particles having a spherical and deformable shape in line with a prevalent fraction of amorphous phase. Conversely, highly semicrystalline polymer nanoparticles exhibit generally an anisotropic morphology. ${ }^{45}$ Semicrystalline polymers generally crystallize through heterogeneous nucleation on impurities or foreign surfaces acting as nucleation seeds. In a nanoconfined miniemulsion environment, the number of particles is several orders of magnitude higher than the number of active heterogeneities. ${ }^{46}$ Therefore, only homogeneous nucleation proceeds, resulting in a decrease of the degree of crystallinity and a significant decrease of the crystallization temperature (also known as supercooling effect).

Figure 4 shows the wide-angle X-ray diffraction (WAXRD) patterns of the two poly(thioether) samples. Independent of the polymer, many sharp Bragg peaks are visible as well as a broad envelope around $20^{\circ}$ assigned to amorphous fraction, indicating respectively the coexistence of crystalline and amorphous domains. At small angles (see the small-angle $\mathrm{X}$ -

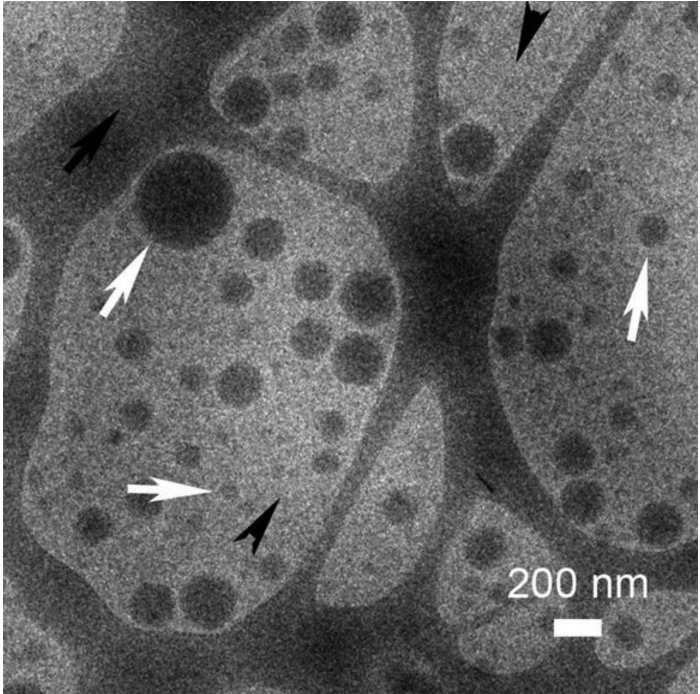

Figure 3. Cryo-TEM image of a representative area of P1 latex. The round-shaped homogeneous particles (indicated by white arrows) have a diameter ranging from 50 to $400 \mathrm{~nm}$. The black arrow shows the lacy carbon supporting film. The solvent areas are fully amorphous due to the high speed of freezing $(10000 \mathrm{~K} / \mathrm{s})$ (arrowhead).

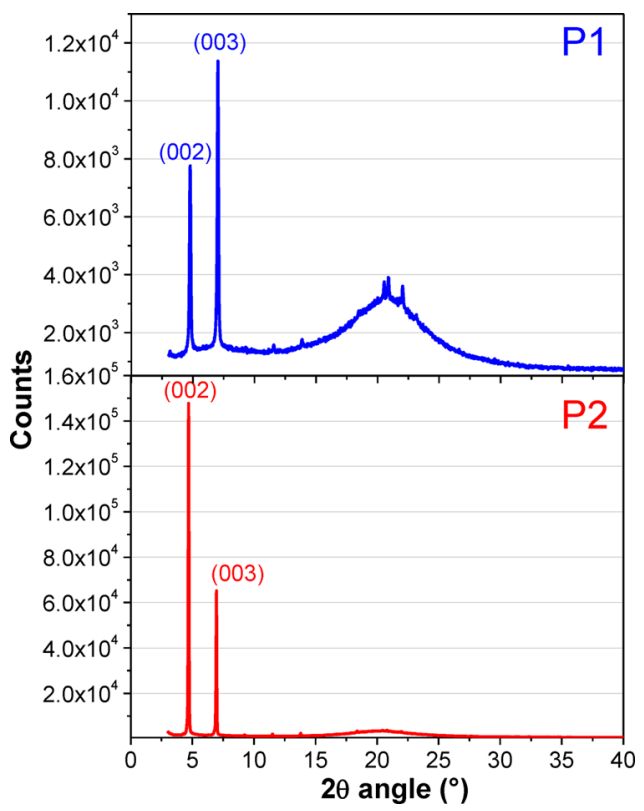

Figure 4. WAXRD patterns of $\mathbf{P 1}$ and $\mathbf{P 2}$ films.

ray diffraction pattern in Figure S5), three discernible Bragg peaks at $2.4^{\circ}, 4.7^{\circ}$, and $7.0^{\circ}$ with associated $d$-spacings of 36.5 , 18.8 , and $12.6 \AA$, respectively, are observed in both cases. They can be readily indexed as the (001), (002), and (003) directions of a lamellar mesostructure, with the typical regular stacks of crystalline lamellae and amorphous interlayers found in semicrystalline polymers. P2 is characterized by a higher degree of crystallinity than P1 as reflected by a much smaller halo on the WAXD pattern. Also present in the film after water evaporation, SDS and HD can both crystallize, ${ }^{47,48}$ but their melting point is around $18{ }^{\circ} \mathrm{C}$, well below the temperature of the XRD analysis $\left(30^{\circ} \mathrm{C}\right)$. Poly(thioether) crystallinity is mainly a consequence of linearity (no branching) and flexibility. Highly favorable for crystallization, chain linearity and structural regularity in a thiol-ene polymerization originate 
from the very low probability of transfer to polymer since transfer to monomer is an intrinsic step of the propagation mechanism having a much higher kinetic constant. Second, the flexibility of the poly(thioether) is conducive to chain packing and stems from the relatively large $\mathrm{C}-\mathrm{S}$ bond length. Obviously, crystallization can be promoted by additional attractive forces involving thioether and ester functional groups, but their low magnitude makes this factor secondary. It should also be noted that crystallization occurs despite the chemical heterogeneity of the film still containing SDS and HD. As expected, the rigid aromatic groups of $\mathbf{P} 1$ reduce flexibility and packing ability, leading to a somewhat lessened degree of crystallinity.

To investigate the crystallization behavior of the two poly(thioether) films, the DSC and TGA thermograms are also shown in Figure 5. From the TGA curves, the first signs of

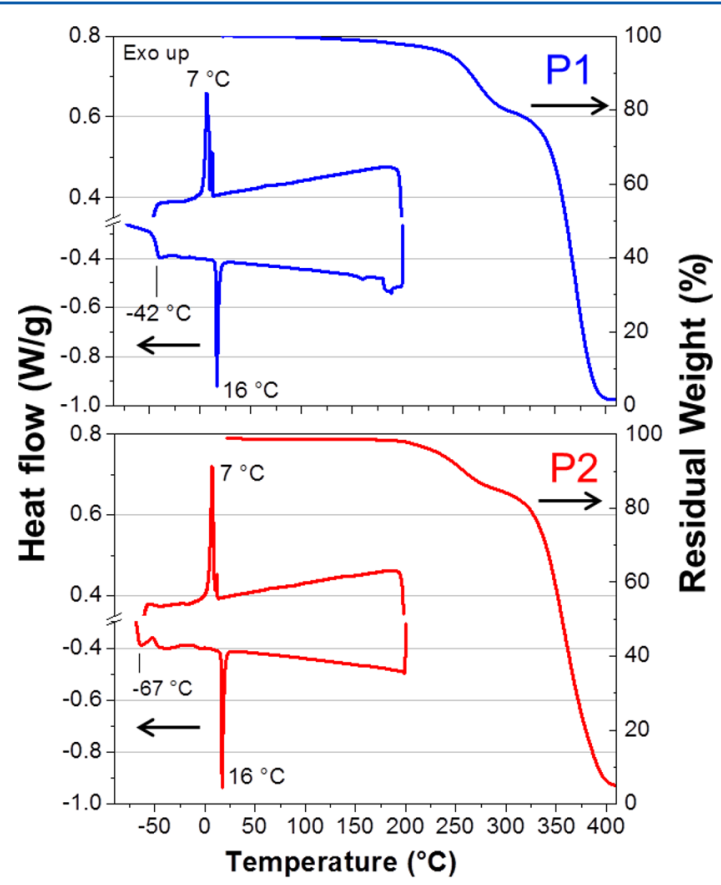

Figure 5. DSC (left $y$-axis) and TGA (right $y$-axis) thermograms of P1 (top) and P2 (bottom) films.

thermal decomposition temperature are manifested as low as $200{ }^{\circ} \mathrm{C}$ in both polymers. On both DSC curves, P1 and P2 show two distinct glass transition temperatures at -42 and -67 ${ }^{\circ} \mathrm{C}$, respectively, indicative of highly flexible chains (see a magnification of the subambient temperature region in Figure S6). The supplement of rigidity provided by the phenyl group in P1 is sufficient to cause an increase of $25{ }^{\circ} \mathrm{C}$ of the $T_{\mathrm{g}}$. However, no melting peak attributed to polymer can be observed although X-ray diffraction yielded a number of welldefined peaks. In contrast to what we have previously reported, ${ }^{15}$ the two thermal transitions at $16{ }^{\circ} \mathrm{C}$ (melting) and $7{ }^{\circ} \mathrm{C}$ (crystallization) come from hexadecane and possibly sodium dodecyl sulfate ${ }^{47,49}$ rather than polysulfide chains. Their observation would not be possible in a fully miscible system and is indicative of a phase separation between poly(thioether), SDS, and hexadecane's crystalline domains. ${ }^{50}$ It is reasonable to deduce that the melting point is too high to be observed before the thermal decomposition which occurs as early as $200{ }^{\circ} \mathrm{C}$. This hypothesis is supported by literature data indicating melting points of poly(methylene sulfide) and poly(ethylene sulfide) at 245 and $216^{\circ} \mathrm{C}$-values much higher than those of poly (methylene oxide) $\left(180^{\circ} \mathrm{C}\right)$ and poly(ethylene oxide) $(68$ $\left.{ }^{\circ} \mathrm{C}\right) .{ }^{51}$

The films were also analyzed with polarized optical microscopy (POM). The alternation of bright (crystallites) and dark (amorphous matrix) areas on Figure 6 in both

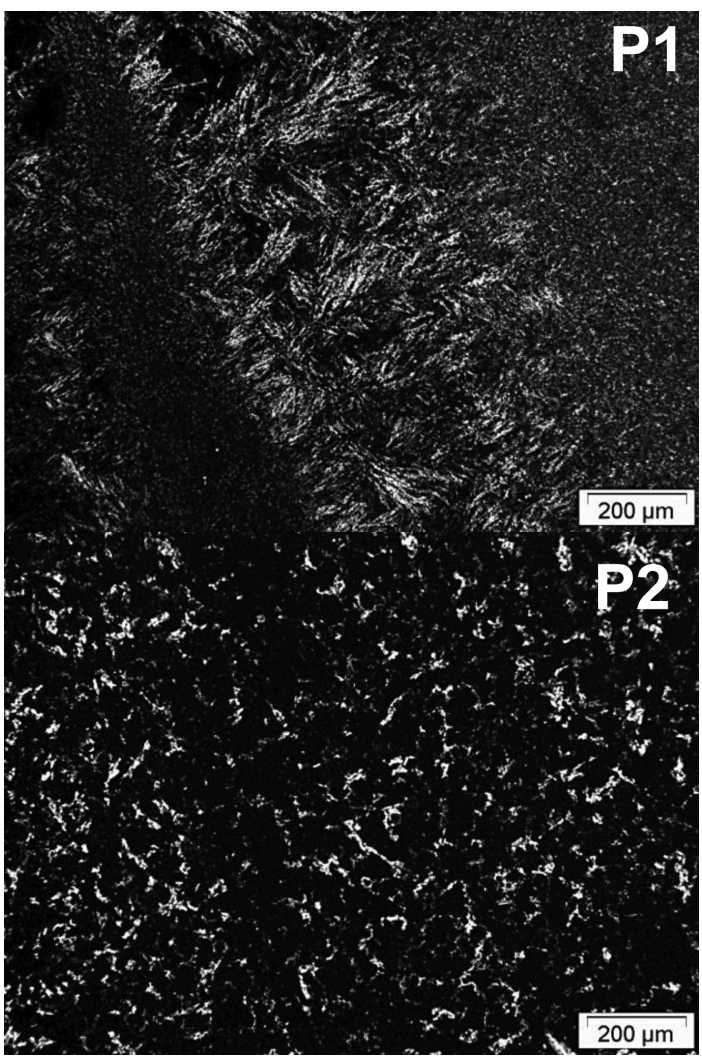

Figure 6. POM pictures in dark field mode of P1 (top) and P2 (bottom) films at ambient temperature.

samples give a first indication of crystalline domains. With P1, large spherulites are formed, indicating a slower crystallization process. In contrast, P2 displays a high number of small nuclei distributed in the film. In both instances, we observed no change of these crystalline macrostructures with temperature up to $130{ }^{\circ} \mathrm{C}$ (see Figure S7). This result shows again that the microcrystals do not result from SDS or hexadecane, both exhibiting a much lower melting temperature (ca. $18{ }^{\circ} \mathrm{C}$ ). Although there is a lack of direct evidence, $\mathrm{XRD}$ and POM data are consistent with a semicrystallinity of the polysulfide films. Clearly, the deposition method is likely to have a strong influence on the crystallization process, and this important question needs to be addressed by future studies.

Dual Hydrolysis- and Oxidation-Responsive Poly(thioether ester) Nanoparticles. Poly(thioether)s such as poly(alkylene sulfide) have been recently proposed as redoxsensitive polymers. ${ }^{52,53}$ Hydrophobic thioether can be oxidized to more polar sulfoxide or sulfone depending on the oxidative conditions, thus driving a significant water solubility increase for the whole polymer chain. As a result, poly(thioether) nanoparticles dispersed in a hydrophilic solvent can act as oxidation-responsive nanocarriers because they are able to decompose by solubilization upon oxidative stress, thus causing the release of their encapsulated hydrophobic content (drug, gene, etc.). Besides other more popular stimuli ( $\mathrm{pH}$, light, etc.), 
Scheme 2. Two Degradation Routes in Water of Poly(thioether ester) P1 Nanoparticles: Hydrogen Peroxide-Induced Oxidation of Thioether and HCl-Catalyzed Hydrolysis of Ester; Oxidation Leads Only to Sulfur(IV) with $\mathrm{H}_{2} \mathrm{O}_{2}{ }^{59}$
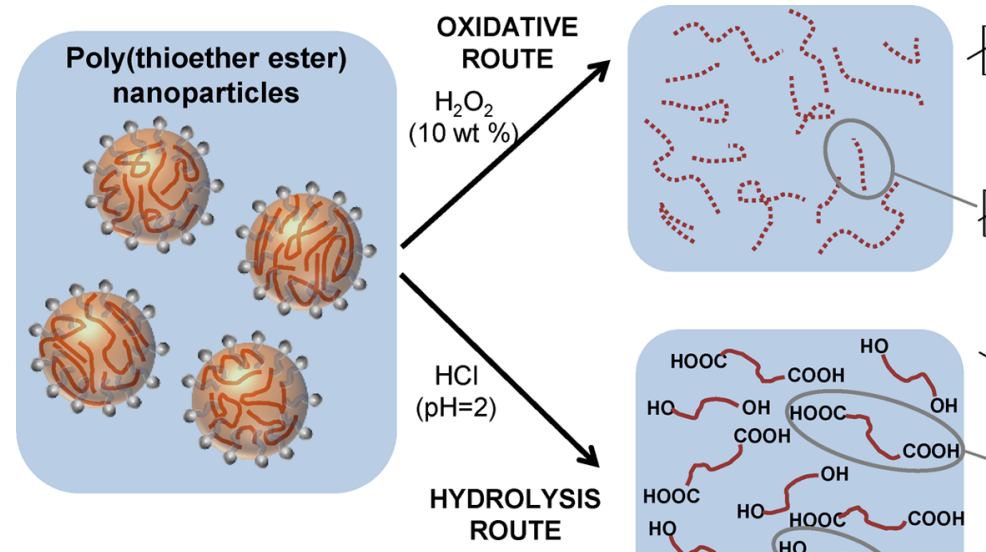

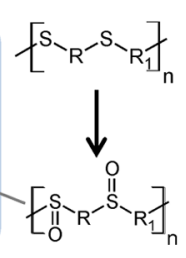

Polysulfide

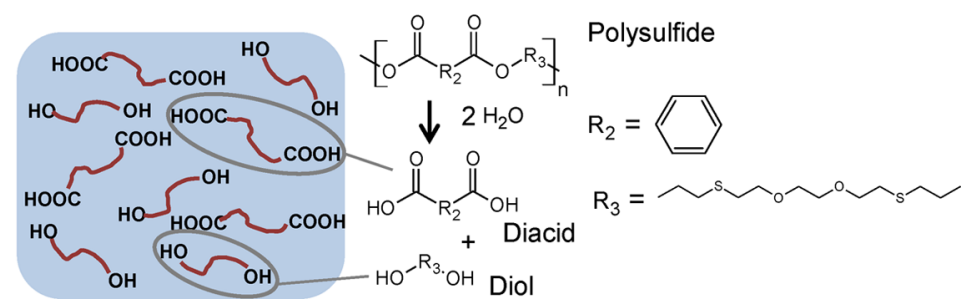

oxidant is highly valuable for drug delivery because reactive oxygen species (ROS) possessing strong oxidizing capabilities play an important role in the progression of inflammatory disorders. ${ }^{54}$ The design of poly(thioether) nanodispersions in water is especially relevant given that thioether are sensitive to a number of mild water-soluble oxidants such as $\mathrm{H}_{2} \mathrm{O}_{2}$ or $\mathrm{NaOCl}^{55}$ To date, the only single-step route to oxidationresponsive poly(thioether) nanoparticles relies on emulsion ring-opening polymerization of propylene sulfide. ${ }^{56,57}$ Although this method has been extensively investigated by Tirelli and Hubbell over the past 10 years as regards particle functionalization or encapsulation, ${ }^{52}$ a novel and efficient method based on thiol-ene photochemistry could provide a simpler and more versatile alternative. In this fourth part, P1 and P2 polysulfide latexes derived from thiol-ene miniemulsion photopolymerization have been considered as dualstimuli-responsive systems. ${ }^{58}$ The combination of thioether and ester bonds in the same polymer backbone make these nanoparticles potentially sensitive to both oxidation and hydrolysis as sketched in Scheme 2.

The nanoparticle response to these two stimuli was assessed by monitoring the attenuance decrease accompanying the loss of turbidity (scattering) as the polymer particles dissolves by oxidation or depolymerizes via hydrolysis. No precipitation was observed, and experiments were performed under constant stirring to eliminate the influence of sedimentation or creaming. Figure 7A shows a series of attenuance spectra of P1 for different characteristic times under oxidative conditions $\left(\left[\mathrm{H}_{2} \mathrm{O}_{2}\right]=10\right.$ wt $\left.\%\right)$ or acid medium $(\mathrm{pH}=2, \mathrm{HCl})$ (the corresponding curve for $\mathbf{P 2}$ is given in Figure S8). Although both routes seem effective for particle chemical modification, hydrolysis leads to faster and more effective decrease of attenuance in the case of P1. Further characterization of the resultant degradation products by SEC (for hydrolysis), FTIR, and NMR could validate the proposed particle degradation mechanisms. Additionally, Figure $7 \mathrm{~B}$ shows the temporal variation of attenuance at a specific wavelength $\lambda=450 \mathrm{~nm}$ $\left(A_{450}\right)$ for the two latexes P1 and P2. Insensitive to oxidation and hydrolysis, a polystyrene-based latex of similar size $\left(D_{\mathrm{p}}=\right.$ $130 \mathrm{~nm}$ ) was also used for control experiments. P1 and P2 latexes show a gradual decrease of $A_{450}$ under oxidative and acid stress leading to a medium becoming much less scattering or completely transparent. The high surface-to-volume ratio of
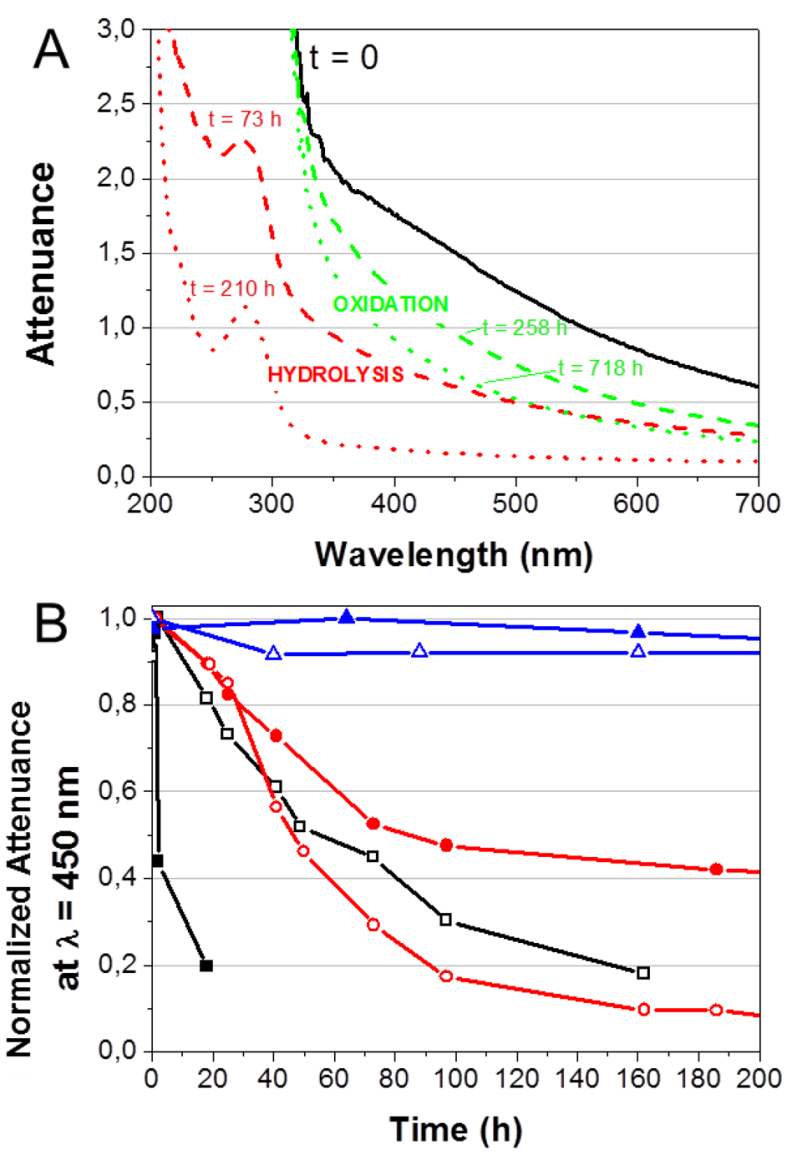

Figure 7. (A) Effect of oxidation ( 10 wt $\% \mathrm{H}_{2} \mathrm{O}_{2}$ solution) and acid hydrolysis $(\mathrm{pH}=2, \mathrm{HCl}$ solution) on the absorption spectrum of diluted latex P1. (B) Normalized attenuance at $450 \mathrm{~nm}$ versus time of different latexes in oxidative medium (full symbols) and acid medium (open symbols): P1 (circle), P2 (square), and a reference polystyrene latex (triangle).

nanoscale particles and low crystallinity in the particle form (vide supra) are both instrumental in the feasibility of the oxidation and hydrolysis reactions. However, the reaction rates between the two latexes are different depending on the degradation route. While the hydrolysis is faster and more effective than oxidation in the case of $\mathbf{P} \mathbf{1}$, the reverse process takes place with P2. In this latter case, a complete transparent 
solution was obtained in less than 1 day in the presence of oxidant. Based on two different mechanisms, both degradation processes may be influenced by polymer microstructure and the reactant solubility.

\section{CONCLUSION}

In summary, linear and film-forming poly(thioether) latexes were synthesized via the step-growth photopolymerization of dithiol-diallyl monomer miniemulsions $\left(C_{\text {monomer }}=20 \mathrm{wt} \%\right)$. Radically mediated, the process retains the robustness of radical chain-growth polymerization while introducing new features: fast reaction kinetics and novel latex/film properties. The versatility of thiol-ene miniemulsion photopolymerization was demonstrated by the study, in parallel, of two thiol-ene monomer couples: EDDT-DAP $(155 \mathrm{~nm})$ and EDDT-DAA $(170 \mathrm{~nm})$. For the former, DBHQ turned out to be an efficient radical inhibitor to ensure a reliable preparation method of the monomer miniemulsion, which must be both photolatent and stable. A salient feature, revealed by real-time NIR spectroscopy techniques, is the very rapid polymerization rates accomplished in the matter of seconds $(<15 \mathrm{~s})$ and resulting in highmolecular-weight polymers $\left(\bar{M}_{\mathrm{n}}=20.3 \mathrm{kDa}\right)$, without adverse effect related to the difference of water solubility between the two comonomers. Under our specific irradiation conditions (1 mm spectroscopic cell, $I=590 \mathrm{~mW} / \mathrm{cm}^{2}$ ), a complete kinetic equivalence was noted between bulk, solution, and miniemulsion systems, indicative of a non-diffusion-limited process. Of high significance is the prospect that inherently fast thiolene photopolymerization can offset the limited penetration depth of turbid media, which is a major difference with chaingrowth polymerization. However, dissipation of the exotherm will be a critical factor and would need to be addressed by appropriate photoreactors and operations.

Extensive characterization based on POM, DSC, XRD, and cryo-TEM revealed a film formation-induced crystallization of poly(thioether films) due to structural regularity and flexibility. In the form of nanoparticles, the polymer showed clear signs of degradation in oxidative media, thus opening avenue for the design of a new array of redox-responsive nanocarriers. Furthermore, a radical step-growth polymerization can create many other opportunities that need to be further explored: complete droplet nucleation, minimization of the residual monomer concentration, high solid contents ( $\geq 50$ wt \%) latexes, etc.

\section{ASSOCIATED CONTENT}

\section{S Supporting Information}

The Supporting Information is available free of charge on the ACS Publications website at DOI: 10.1021/acs.macromol.5b02512.

Thiol-ene polymerization mechanism (Scheme S1), RTFTNIR setup (Scheme S2), size reproducibility data (Table S1), fitted polymerization kinetics (Figure S1), ${ }^{1} \mathrm{H}$ NMR spectrum of $\mathbf{P 1}$ (Figure S2), SEC traces of P1 synthesized by miniemulsion (M1), solution (S1), and bulk (B1) (Figure S3), effect of irradiance, PI, and $C_{\text {monomer }}$ on reaction kinetics (Figure S4), small-angle XRD pattern (Figure S5), DSC thermogram (Figure S6), POM images upon heating (Figure S7), degradation experiments of P2 latex (Figure S8) (PDF)

\section{AUTHOR INFORMATION}

\section{Corresponding Author}

*E-mail abraham.chemtob@uha.fr; Fax +33 3896087 99; Tel +33 389608804 (A.C.).

\section{Notes}

The authors declare no competing financial interest.

\section{ACKNOWLEDGMENTS}

The authors gratefully acknowledge the financial support of the French National Research Agency (ANR, Programme Chimie Durable-Industries-Innovation) under Contract ANR-2012CDII-006-02. They express their gratitude to Dr. Cyrille Boyer (Associate Professor in the School of Chemical Engineering, University of New South Wales, Australia), who provided expertise and advice on analysis of the DSC thermograms.

\section{REFERENCES}

(1) Urban, D.; Takamura, K. Polymer Dispersions and their Industrial Applications; Wiley-VCH: Darmstadt, 2002.

(2) Asua, J. M. Emulsion Polymerization: From Fundamental Mechanisms to Process Developments. J. Polym. Sci., Part A: Polym. Chem. 2004, 42, 1025-1041.

(3) Asua, J. M. Challenges for Industrialization of Miniemulsion Polymerization. Prog. Polym. Sci. 2014, 39, 1797-1826.

(4) Kostjuk, S. V.; Ganachaud, F. Cationic Polymerization of Vinyl Monomers in Aqueous Media: From Monofunctional Oligomers to Long-Lived Polymer Chains. Acc. Chem. Res. 2010, 43, 357-367.

(5) Korthals, B.; Morant-Mis̃ana, M. C.; Schmid, M.; Mecking, S. Functionalization of Polymer Nanoparticles by Thiol-Ene Addition. Macromolecules 2010, 43, 8071-8078.

(6) Crespy, D.; Landfester, K. Miniemulsion Polymerization as a Versatile Tool for the Synthesis of Functionalized Polymers. Beilstein J. Org. Chem. 2010, 6, 1132-1148.

(7) Cunningham, M. F. Controlled/Living Radical Polymerization in Aqueous Dispersed Systems. Prog. Polym. Sci. 2008, 33, 365-398.

(8) Zetterlund, P. B.; Kagawa, Y.; Okubo, M. Controlled/Living Radical Polymerization in Dispersed Systems. Chem. Rev. 2008, 108, 3747-3794

(9) Guyot, A.; Landfester, K.; Joseph Schork, F.; Wang, C. Hybrid Polymer Latexes. Prog. Polym. Sci. 2007, 32, 1439-1461.

(10) Schwartz, M.; Baumstark, R. Water-based Acrylates for Decorative Coatings; Vincentz: Hannover, 2001.

(11) Marvel, C. S.; Chambers, R. R. Polyalkylene Sulfides from Diolefins and Dimercaptans. J. Am. Chem. Soc. 1948, 70, 993-998.

(12) Dénès, F.; Pichowicz, M.; Povie, G.; Renaud, P. Thiyl Radicals in Organic Synthesis. Chem. Rev. 2014, 114, 2587-2693.

(13) Sawicki, L. A.; Kloxin, A. M. Design of Thiol-Ene Photoclick Hydrogels using Facile Techniques for Cell Culture Applications. Biomater. Sci. 2014, 2, 1612-1626.

(14) Durham, O. Z.; Krishnan, S.; Shipp, D. A. Polymer Microspheres Prepared by Water-Borne Thiol-Ene Suspension Photopolymerization. ACS Macro Lett. 2012, 1, 1134-1137.

(15) Jasinski, F.; Lobry, E.; Tarablsi, B.; Chemtob, A.; CroutxéBarghorn, C.; Le Nouen, D.; Criqui, A. Light-Mediated Thiol-Ene Polymerization in Miniemulsion: A Fast Route to Semicrystalline Polysulfide Nanoparticles. ACS Macro Lett. 2014, 3, 958-962.

(16) Amato, D. V.; Amato, D. N.; Flynt, A. S.; Patton, D. L. Functional, Sub-100 nm Polymer Nanoparticles via Thiol-Ene Miniemulsion Photopolymerization. Polym. Chem. 2015, 6, 56255632.

(17) Durham, O.; Shipp, D. Suspension "Click” Polymerizations: Thiol-Ene Polymer Particles Prepared with Natural Gum Stabilizers. Colloid Polym. Sci. 2015, 293, 2385-2394.

(18) Durham, O. Z.; Shipp, D. A. Suspension Thiol-Ene Photopolymerization: Effect of Stabilizing Agents on Particle Size and Stability. Polymer 2014, 55, 1674-1680. 
(19) Tan, J.; Li, C.; Zhou, J.; Yin, C.; Zhang, B.; Gu, J.; Zhang, Q. Fast and Facile Fabrication of Porous Polymer Particles via Thiol-Ene Suspension Photopolymerization. RSC Adv. 2014, 4, 13334-13339.

(20) Wang, C.; Chatani, S.; Podgorski, M.; Bowman, C. N. ThiolMichael Addition Miniemulsion Polymerizations:Functional Nanoparticles and Reactive Latex Films. Polym. Chem. 2015, 6, 3758-3763.

(21) Wang, C.; Podgorski, M.; Bowman, C. N. Monodisperse Functional Microspheres from Step-Growth "Click" Polymerizations: Preparation, Functionalization and Implementation. Mater. Horiz. 2014, 1, 535-539.

(22) Amato, D. N.; Amato, D. V.; Narayanan, J.; Donovan, B. R.; Douglas, J. R.; Walley, S. E.; Flynt, A. S.; Patton, D. L. Functional, Composite Polythioether Nanoparticles via Thiol-Alkyne Photopolymerization in Miniemulsion. Chem. Commun. 2015, 51, 1091010913.

(23) Tan, J.; Li, C.; Li, H.; Zhang, H.; Gu, J.; Zhang, B.; Zhang, H.; Zhang, Q. Water-Borne Thiol-Isocyanate Click Chemistry in Microfluidics: Rapid and Energy-Efficient Preparation of Uniform Particles. Polym. Chem. 2015, 6, 4366-4373.

(24) Workman, J.; Weyer, L. Practical Guide to Interpretive Nearinfrared Spectroscopy; CRC Press: New York, 2007; p 346.

(25) Ibrahim, A.; Maurin, V.; Ley, C.; Allonas, X.; Croutxe-Barghorn, C.; Jasinski, F. Investigation of Termination Reactions in Free Radical Photopolymerization of UV Powder Formulations. Eur. Polym. J. 2012, $48,1475-1484$.

(26) Mengual, O.; Meunier, G.; Cayré, I.; Puech, K.; Snabre, P. TURBISCAN MA 2000: Multiple Light Scattering Measurement for Concentrated Emulsion and Suspension Instability Analysis. Talanta 1999, 50, 445-456.

(27) Schork, F. J.; Luo, Y.; Smulders, W.; Russum, J. P.; Butté, A.; Fontenot, K. Miniemulsion Polymerization. In Polymer Particles; Okubo, M., Ed.; Springer-Verlag: Heidelberg, 2005; p 129.

(28) Esfandiari, P.; Ligon, S. C.; Lagref, J. J.; Frantz, R.; Cherkaoui, Z.; Liska, R. Efficient Stabilization of Thiol-Ene Formulations in Radical Photopolymerization. J. Polym. Sci., Part A: Polym. Chem. 2013, 51, 4261-4266.

(29) Hoyle, C. E.; Lee, T. Y.; Roper, T. Thiol-Enes: Chemistry of the Past with Promise for the Future. J. Polym. Sci, Part A: Polym. Chem. 2004, 42, 5301-5338.

(30) Xia, H.; Wang, Q.; Liao, Y.; Xu, X.; Baxter, S. M.; Slone, R. V.; Wu, S.; Swift, G.; Westmoreland, D. G. Polymerization Rate and Mechanism of Ultrasonically Initiated Emulsion Polymerization of $\mathrm{n}$ Butyl Acrylate. Ultrason. Sonochem. 2002, 9, 151-158.

(31) Manea, M.; Chemtob, A.; Paulis, M.; de la Cal, J. C.; Barandiaran, M. J.; Asua, J. M. Miniemulsification in High-Pressure Homogenizers. AIChE J. 2008, 54, 289-297.

(32) Jafari, S. M.; Assadpoor, E.; He, Y.; Bhandari, B. Re-Coalescence of Emulsion Droplets during High-Energy Emulsification. Food Hydrocolloids 2008, 22, 1191-1202.

(33) Hoyle, C. E.; Bowman, C. N. Thiol-Ene Click Chemistry. Angew. Chem., Int. Ed. 2010, 49, 1540-1573.

(34) Beuermann, S.; Buback, M. Rate Coefficients of Free-Radical Polymerization Deduced from Pulsed Laser Experiments. Prog. Polym. Sci. 2002, 27, 191-254.

(35) Nakamura, T.; Okubo, M. Mechanistic Investigation of Particle Size Effects in TEMPO- Mediated Radical Polymerization of Styrene in Aqueous Miniemulsion. Macromolecules 2007, 40, 8663-8672.

(36) Nakamura, T.; Zetterlund, P. B.; Okubo, M. Particle Size Effects in TEMPO-Mediated Radical Polymerization of Styrene in Aqueous Miniemulsion. Macromol. Rapid Commun. 2006, 27, 2014-2018.

(37) Bechthold, N.; Landfester, K. Kinetics of Miniemulsion Polymerization As Revealed by Calorimetry. Macromolecules 2000, 33, 4682-4689.

(38) Aizpurua, I.; Amalvy, J. I.; Barandiaran, M. J. Influence of the Polymeric Hydrophobe on the Kinetics of Vinyl Acetate Miniemulsion Polymerization. Colloids Surf., A 2000, 166, 59-66.

(39) Octanol-water partition coefficients (KOW) of I2959 and I651 are respectively 0.84 and 3.42 (Safety Data Sheet) at $25{ }^{\circ} \mathrm{C}$. KOW (I2959) value is low enough to enable its dissolution in the aqueous phase $(5 \mathrm{~g} / \mathrm{L})$; however, it suggests a partition between the monomer and aqueous phases.

(40) Cramer, N. B.; Bowman, C. N. Kinetics of Thiol-Ene and Thiol-Acrylate Photopolymerizations with Real-Time Fourier Transform Infrared. J. Polym. Sci., Part A: Polym. Chem. 2001, 39, 33113319.

(41) Guyot, A.; Chu, F.; Schneider, M.; Graillat, C.; McKenna, T. F. High Solid Content Latexes. Prog. Polym. Sci. 2002, 27, 1573-1615.

(42) Alfano, O. M.; Negro, A. C.; Cabrera, M. I.; Cassano, A. E. Scattering Effects Produced By Inert Particles In Photochemical Reactors. 1. Model And Experimental Verification. Ind. Eng. Chem. Res. $1995,34,488-499$.

(43) Takahashi, Y.; Tadokoro, H.; Chatani, Y. Structure of Polyethylene Sulfide. J. Macromol. Sci., Part B: Phys. 1968, 2, 361-367.

(44) Vinas, J.; Dufils, P. E. Poly(Vinylidene Chloride). In Ullmann's Encyclopedia of Industrial Chemistry; Wiley-VCH: Berlin, 2012.

(45) Staff, R. H.; Lieberwirth, I.; Landfester, K.; Crespy, D. Preparation and Characterization of Anisotropic Submicron Particles From Semicrystalline Polymers. Macromol. Chem. Phys. 2012, 213, $351-358$.

(46) Michell, R. M.; Blaszczyk-Lezak, I.; Mijangos, C.; Müller, A. J. Confinement Effects on Polymer Crystallization: From Droplets to Alumina Nanopores. Polymer 2013, 54, 4059-4077.

(47) Pereira, R. F. P.; Valente, A. J. M.; Burrows, H. D.; de Zea Bermudez, V.; Carvalho, R. A.; Castro, R. A. E. Structural Characterization of Solid Trivalent Metal Dodecyl Sulfates: From Aqueous Solution to Lamellar Superstructures. RSC Adv. 2013, 3, $1420-1433$.

(48) Smith, L. A.; Duncan, A.; Thomson, G. B.; Roberts, K. J.; Machin, D.; McLeod, G. Crystallisation of Sodium Dodecyl Sulphate from Aqueous Solution: Phase Identification, Crystal Morphology, Surface Chemistry and Kinetic Interface Roughening. J. Cryst. Growth 2004, 263, 480-490.

(49) Vanapalli, S. A.; Palanuwech, J.; Coupland, J. N. Stability of Emulsions to Dispersed Phase Crystallization: Effect of Oil Type, Dispersed Phase Volume Fraction, and Cooling Rate. Colloids Surf., A 2002, 204, 227-237.

(50) Chaiyasat, P.; Suzuki, T.; Minami, H.; Okubo, M. Thermal Properties of Hexadecane Encapsulated in Poly(divinylbenzene) Particles. J. Appl. Polym. Sci. 2009, 112, 3257-3266.

(51) Sasanuma, Y.; Hayashi, Y.; Matoba, H.; Touma, I.; Ohta, H.; Sawanobori, M.; Kaito, A. Conformational Analysis of Poly(propylene sulfide). Macromolecules 2002, 35, 8216-8226.

(52) Song, C.-C.; Du, F.-S.; Li, Z.-C. Oxidation-Responsive Polymers for Biomedical Applications. J. Mater. Chem. B 2014, 2, 3413-3426.

(53) Huo, M.; Yuan, J.; Tao, L.; Wei, Y. Redox-Responsive Polymers for Drug Delivery: From Molecular Design to Applications. Polym. Chem. 2014, 5, 1519-1528.

(54) Joshi-Barr, S.; de Gracia Lux, C.; Mahmoud, E.; Almutairi, A. Exploiting Oxidative Microenvironments in the Body as Triggers for Drug Delivery Systems. Antioxid. Redox Signaling 2014, 21, 730-754.

(55) Jeanmaire, D.; Laliturai, J.; Almalik, A.; Carampin, P.; Richard, d. A.; Lallana, E.; Evans, R.; Winpenny, R. E. P.; Tirelli, N. Chemical Specificity in REDOX-Responsive Materials: The Diverse Effects of Different Reactive Oxygen Species (ROS) on Polysulfide Nanoparticles. Polym. Chem. 2014, 5, 1393-1404.

(56) Rehor, A.; Tirelli, N.; Hubbell, J. A. A New Living Emulsion Polymerization Mechanism: Episulfide Anionic Polymerization. Macromolecules 2002, 35, 8688-8693.

(57) Rehor, A.; Hubbell, J. A.; Tirelli, N. Oxidation-Sensitive Polymeric Nanoparticles. Langmuir 2005, 21 (1), 411-417.

(58) Sokolovskaya, E.; Rahmani, S.; Misra, A. C.; Bräse, S.; Lahann, J. Dual-Stimuli-Responsive Microparticles. ACS Appl. Mater. Interfaces 2015, 7, 9744-9751.

(59) Carampin, P.; Lallana, E.; Laliturai, J.; Carroccio, S. C.; Puglisi, C.; Tirelli, N. Oxidant-Dependent REDOX Responsiveness of Polysulfides. Macromol. Chem. Phys. 2012, 213, 2052-2061. 